\title{
WHAT IS THE 'FUTURE' OF GREEK? TOWARDS A PRAGMATIC ANALYSIS
}

\author{
MICHAEL CHIOU \\ Athens Metropolitan College \\ mchiou1234@gmail.com
}

\begin{abstract}
The paper investigates the problems related to futurity and modality in modern Greek. The discussion of Greek temporal future expressions is conducted with reference to relevant literature from the areas of English linguistics, cognitive studies and pragmatics. The focus is on the status of future-oriented expressions and the question whether they are primarily epistemic in nature, whether they are tense-based, or modality-based. It is argued that the future tense in Greek has a modal semantic base conveying epistemic modality and that the preferred future prospective reading is a pragmatic development of the semantic modal base. The author further suggests that the future reading is a kind of presumptive meaning which follows from the neo-Gricean Principle of Informativeness, known as the I-principle (Levinson 2000) being a generalised interpretation which does not depend on contextual information.
\end{abstract}

Keywords: pragmatics, neo-Gricean pragmatics, modality, tense, Greek

\section{Setting the scene}

It is well known that futurity and modality are interrelated in such a way across languages that there is an ongoing debate concerning the status of future tenses as markers of tense or of modality (e.g. Comrie 1985, Enç 1996, Sarkar 1998, Ludlow 1999, Copley 2009, Condoravdi 2002, Squartini 2004, Jaszczolt 2006, Kissine 2008, Mari 2009, 2010 Giannakidou \& Mari 2012, 2013, 2014). Modern Greek is not different in this respect and therefore the question whether the so-called future tense has a temporal or a modal basis is still under discussion (see Condoravdi 2002, Giannakidou 2009, 2012, Giannakidou \& Mari 2012, 2013, 2014, Tsangalidis 1999 among others).

Modern Greek forms a periphrastic future tense by employing the particle tha $(\theta \alpha=w i l l)$, usually referred to as the future marker (see Philippaki-Warburton 1994, Rivero 1994 among others) followed by the imperfective non-past or the perfective nonpast verb forms ${ }^{1}$ (henceforth INP and PNP respectively). Nevertheless, as it will be shown, only the combination of tha and the PNP gives the 'pure' future interpretation, while tha combined with the INP systematically conveys epistemic non-future modal readings.

\footnotetext{
${ }^{1}$ In traditional grammar the combination of tha with the PNP is termed 'simple future' while the combination with the INP is termed 'future continuous'.
} 
In recent work (cf. Giannakidou 2009, 2012, Giannakidou \& Mari 2012, 2013, 2014 and Tsangalidis 1999), it has been argued that the particle tha is not a typical future tense marker. In particular, Giannakidou \& Mari $(2012$, 2013, 2014) propose, among other things, that the particle tha is an epistemic modal operator with a present (now) perspective. Moreover, the Greek PNP verb form cannot function as an independent tense form (Holton et al. 1997) and therefore it is treated as a non-deictic time marker. If this line of analysis is correct, and there is nothing in the semantics of tha constructions that functions as a future tense marker, we need to account for the future prospective reading conveyed by the combination of tha and the PNP.

Based on this, I argue that the future tense in Greek has a modal semantic base conveying epistemic modality, in the spirit of Giannakidou (2009, 2012) and Giannakidou \& Mari (2012, 2013, 2014), and that the preferred future prospective reading is a pragmatic development of the semantic modal base. It can further be proposed that the future prospective reading is a kind of presumptive meaning which follows from the principles of language use and, more precisely, from the neo-Gricean Principle of Informativeness, known as the I-principle (Levinson 2000), since it is not part of 'what is said,' but it is a generalised interpretation which does not depend on contextual information.

The structure of the paper is as follows. In section 2, I focus on the typology and the properties of future constructions. In section 3, I outline the current literature focusing on the study of future constructions and future-time reference; in section 4, I present the neo-Gricean pragmatics theory of communication focusing mainly on the I-principle and, finally, in section 5, I further develop the pragmatic analysis of future-time reference in Modern Greek.

\section{Facts on tha-constructions: Epistemic and future uses}

\subsection{Tense, aspect and verb morphology}

In Modern Greek the verb form is inflected for the grammatical categories of tense and aspect. Following this, there is a morphological distinction between past and non-past, in terms of tense, and perfective and imperfective in terms of aspect. The importance of aspect in Modern Greek is emphasised by the fact that all tenses, moods and voices are marked for either the perfective or the imperfective aspect (Joseph 1983, Holton et al. 1997, Tsangalidis 1999). The imperfective aspect is used to mark a progressive, habitual or repeated action, whereas the perfective aspect marks an action which is perceived as a completed whole (Xidopoulos 1996, Holton et al. 1997).

The combinations of tense and aspect give us four morphologically distinct verb forms which are exemplified in the following table (Mackridge 1985, Holton et al. 1997):

(1) graf -o (INP) write IMP-1SG.NON-PAST

'I am writing (right now).'

'I write (generally).'
(2) * grap $-s-o$ (PNP) write-PERF.1SG.NON-PAST (no exact English equivalent) 
(3) $e$-graf - $a$ (IP)

PAST-write-IMP.1SG.PAST

'I used to write.'

'I was writing.'
(4) $e$ - grap $-s-a(\mathrm{PP})$

PAST-write-PERF.1SG.PAST

'I wrote.'

There are two past forms, namely, the imperfective past (IP) in (3) and the perfective past (PP) in (4), and two non-past forms, namely, the imperfective non-past (henceforth INP) in (1) and the perfective non-past (henceforth PNP) in (2). Traditional grammar treats the verb form in (1) as a present tense form, yet Giannakidou (2009) argues that non-past verb forms are not simply equivalent to present. The verb form in (2), i.e. the PNP, is not possible without the presence of certain particles (such as na, as, tha and an) as illustrated in examples (5) - (7) below. This is the reason why it is referred to as the 'dependent' form (Holton et al. 1997: 220).

(5) *O Nikos grapsi ena grama the Nikos write PNP a letter

'Nikos write a letter.'

(6) As grapsi o Nikos ena grama Let write PNP the Nikos a letter 'Let Nikos write a letter.'

(7) $\mathrm{O}$ Nikos tha grapsi ena grama the Nikos will write PNP a letter 'Nikos will write a letter.'

In this study we are going to focus on the PNP and INP verb forms since these two forms are used in the formation of the future constructions.

\subsection{The typology of future tense and tha-constructions}

As it is obvious from the discussion so far, in Modern Greek, future tense is not morphologically marked in the verb form. According to traditional grammar, future tense in Modern Greek is formed with the particle tha followed by the PNP (as in 8) or INP verb forms (as in 9).

(8) O Nikos tha petaksi gia to Londino. the Nikos will fly PNP for the London 'Nikos will fly to London.'

(9) O Nikos tha petai gia to Londino avrio the Nikos will fly INP for the London tomorrow 'Nikos will be flying to London tomorrow.'

The combination of th $\alpha$ with PNP, as in (8), is used to "express an action which will take place and be completed at a future point in time" (Holton et al. 1997: 227). This type of future is dubbed in traditional terms as the 'simple future'. Alternatively, when tho is 
combined with the INP, as in (9), "it describes an action which will be taking place in the future either as a habitual event, or as a continuous, progressive one" (Holton et al. 1997: 226).

It has to be noted though that in examples like (9), future-time reference seems to arise from the use of the time adverbial 'avrio' (Eng. tomorrow). If the adverb is removed, and there is no specific context, the future interpretation does not survive.

(10) O Nikos tha petai gia to Londino the Nikos will fly INP for the London

'Nikos will be flying to London.' (now)

In such cases, combinations of tha with INP are most frequently interpreted as epistemic present (Giannakidou 2012), expressing a highly strong possibility and an inference about the state of affairs at the utterance time based on the evidence that the speaker has. In such contexts, tha constructions do not have the force of a pure future tense but they can be glossed as 'most probably/possibly' making reference to the utterance time. Giannakidou (2012) and Giannakidou \& Mari (2012) also argue that tha, when combined with INP, exhibits evidential behaviour and it is very similar to the evidential modal 'prepi' (Eng. must). In this sense, tha with INP is co-operatively used when the speaker lacks direct evidence about the relevant situation. For instance, in example (10) by uttering ' $o$ Nikos tha petai' (Nikos will be flying), the speaker communicates that he does not have direct evidence with regard to the truth of the proposition and that he is just making an inference based on indirect evidence.

This epistemic present reading can be further reinforced by the use of high probability adverbs such as malon (Eng. probably) (cf. Holton et al. 1997, Giannakidou \& Mari 2012).

(11) O Nikos malon tha petai gia to Londino the Nikos probably will fly INP for the London 'Nikos will be probably flying to London.' (now)

Nevertheless, the epistemic present interpretation is not the preferred one when the verb is in the $1^{\text {st }}$ or the $2^{\text {nd }}$ person. Consider the examples:

(12) ?Tha petao gia to Londino tora Will fly INP, 1 sin for the London now ?'I will be flying to London now.'

(13) ?Tha petas gia to Londino tora Will fly INP, 2sin for the London now ?'You will be flying to London now.'

(14) Tha petas gia to Londino avrio Will fly INP, 2SIN for the London tomorrow 'You will be flying to London tomorrow.'

The addition of an adverb referring to the utterance time such as 'tora' (Eng. now) renders examples (12) and (13) odd, if not unacceptable. Yet, there is no problem at all with the future time adverb 'avrio' (Eng. tomorrow) as in (14). The fact that the $1^{\text {st }}$ and 
the $2^{\text {nd }}$ person are more likely to express futurity than the third person, which favours epistemic present readings, is also observed in Tsangalidis (1999) following Heine (1995).

According to traditional grammars the future tense or simple future, as it is usually dubbed, is restricted to the combination of tha followed by the PNP.

(15) O Nikos tha petksi gia to Londino

The Nikos will fly PNP for the London

'Nikos will fly to London.' (in the future)

The preferred future interpretation of tha with PNP combinations is not determined by the presence or absence of an adverb of time as it is the case with tha combined with the INP. The time adverbial just anchors the event described by the verb at a specific point in the future.

(16) O Nikos tha petksi gia to Londino avrio/ se tris meres...

The Nikos will fly PNP for the London tomorrow/in three days...

'Nikos will fly to London tomorrow/in three days...'

The only case in which tha and PNP combination does not convey a temporal (future) interpretation is when it is used to describe habitual timeless actions or to indicate obligation. Consider the examples (17) and (18) respectively (Holton et al. 1997):

(17) Kathe proi tha sikothi, tha pji to kafedaki tu, tha djavasi tin efimerida tu ke kata tis 8.30 tha figi gia to grafio tu

'Every morning he will get up, drink his coffee, read his newspaper and at approximately 8.30 he will leave for the office.'

(18) Oxi tha mu to epistrepsis afto to grama amesos!

'No, you will [must] give this letter back to me immediately.'

In examples such as (17), adverbs of time such as 'tora' (Eng. now), 'avrio' (Eng. tomorrow) which are always compatible with tha and PNP constructions are not acceptable, which shows that a temporal reading is not intended in such contexts.

\section{Future in Modern Greek: an overview of relevant literature}

\subsection{Particle tha as a future gram-type}

Within the framework of a comparative study between will constructions in English and tha constructions in Modern Greek, by means of which future-time reference is expressed, Tsangalidis (1999) proposes a theory which permits future to be defined independently of the core categories of tense and modality.

More precisely, the analysis in Tsangalidis (1999) is built upon the notion of "grammatical morpheme" or "gram-type" introduced in Dahl (1985) and Bybee \& Dahl 
(1989). The term "gram-type" refers to cross-linguistic categories which are instantiated in each language by a specific type of "gram". "Gram" in its turn refers to the notion of grammatical morpheme. As Bybee et al. (1994: 2) explain, "grammatical morphemes are closed-class elements whose class membership is determined by some unique grammatical behaviour, such as position of occurrence, co-occurrence restrictions, or other distinctive interactions with other linguistic elements". Moreover, these grammatical morphemes or 'grams' may appear in various types in terms of their form, ranging from affixes to complex constructions and they are "identifiable by their semantic foci" Bybee \& Dahl (1989: 52). In this sense the notion of the "gram-type" cuts across the traditional categories such as tense, aspect, or mood.

It is argued that tha is not a typical future tense marker, but it is not a modal operator either. Consequently, according to Tsangalidis (1999), tha is best described as an instance of the 'future gram-type'. The semantic content of 'future gram-types' indicates that "the speaker predicts a situation will occur subsequent to the speech event" (Bybee \& Dahl 1989: 55). As a result, the category of the 'future' can be approached in an alternative way, rendering thus irrelevant the debate over its temporal or modal status. As Tsangalidis (1999: 255) observes, "future-grams [...] are seen as autonomous entities [...] and their definition in terms of polysemic associations of diachronically related senses does not exclude their use as markers of temporal, aspectual and modal notions".

The main proposal in Tsangalidis (1999) is that the particle tha qualifies neither as a prototypical modal, nor as a pure future tense marker. Accordingly, a future-gram type status of tha is proposed, which allows for a description independent of membership in either a temporal or a modal category. Following Tsangalidis (1999: xi), this line of analysis has "advantages over any attempt to decide on the centrality of either tense or modality in the semantics of future markers or any attempt to recognize distinct underlying elements which only happen to be homophonous in these languages."

Concerning the interpretation of tha constructions, Tsangalidis (1999) concludes that: a) tha combined with perfective past (PP) gives pure epistemic past readings; b) tha combined with the PNP gives pure non-epistemic future readings; and c) all other combinations are open to both temporal and modal readings. In addition, it is also put forward that "the default interpretation (of tha) is dependent on the form of the lexical verb - and crucially on its aspectual and temporal characteristics" (Tsangalidis 1999: 253).

Beginning with the dependent form, Tsangalidis (1999) assumes the now widely accepted view that it is a typical PNP form and not a subjunctive form ${ }^{2}$. What is more, following the literature on aspect ${ }^{3}$ according to which perfectives when combined with non-past generate a contradiction (since perfective events cannot occur at the same time with perfective speech events and therefore, they cannot practically refer to the utterance time), Tsangalidis (1999) explains why the PNP can only receive pure future or habitual interpretations. Finally, the fact that PNP forms are non-specific and non-past can account for their dependent status (Tsangalidis 1999).

Turning to tha with INP constructions, Tsangalidis (1999) supports that the epistemic present reading should not be considered the default one since epistemically modalised

\footnotetext{
${ }^{2}$ The view that 'dependent' or 'yrapso' forms are not subjunctives is put forward in Veloudis \& Philippaki-Warburton (1983) and Philippaki-Warburton (1992).

${ }^{3}$ Cf. e.g. Dahl (1985), Comrie $(1976,1985)$ and Smith (1991).
} 
statements about the speaker and the addressee do not normally hold. As a result, it is proposed that the combination of tha with INP is underspecified for tense which means that tha with INP "does not force a future time reference as such - but rather "prediction"” (Tsangalidis 1999: 212). As it is explained, this prediction normally refers to the future (hence the potential future time reference), however, in certain contexts (such as the case of statives, progressives and imperfectives) prediction can equally refer to the present; in these cases the contribution of the particle tha is epistemic modality rather than futurity. What follows then is an ambiguity between future and epistemic present time interpretations which, according to Tsangalidis (1999), can be best accounted for by the analysis of tha as a 'future gram-type'.

\subsection{The Greek future particle as an epistemic modal}

In a more recent study, Giannakidou $(2009,2012)$ and Giannakidou \& Mari (2012) put forward an alternative analysis of the particle tha and future-time reference in Modern Greek. The main proposal is that the particle tha is not a future tense marker but a modality operator. This is proposal is based on the non-future readings of tha when combined mainly with the INP and the past forms but it is also related to the interaction of tha with modal adverbials (Giannakidou 2012).

To begin with, it is argued that in cases where tha is combined with the INP and the PP there is a pure epistemic reading. Consider the examples below (form Giannakidou 2012):

(19) $\mathrm{i}$ Ariadni tha kimate tora The Ariadne will sleep INP, 3sin now 'Ariadne must be sleeping now.'

(20) $\mathrm{i}$ Ariadni tha ine giatros The Ariadne will be 3 sin doctor 'Ariadne must be a doctor.'

In the examples above, the preferred interpretation is epistemic and inferential. The speaker expresses a kind of inferential assessment about what Ariadne might be or might be doing based on the knowledge and the information that he has. As Giannakidou (2012: 51) notes, tha with INP constructions also have "sensitivity to the nature of evidence: if I have direct evidence to the truth of the sentence, tha is unacceptable".

Furthermore, it is observed that tha co-occurs with adverbs that convey very strong possibility and necessity as it happens with the necessity modal 'prepi' (must) which can also combine with tha as it is illustrated below:

(21) i Ariadne $\{$ malon/\#isos $\}$ tha prepi na efije

The Ariadne probably will must suBj left

'Ariadne probably must have left.'

(22) i Ariadne (tha) prepi na efije

The Ariadne will must suBj left 
'Ariadne probably must have left.'

Giannakidou (2012: 52) claims that "given the co-compatibility of tha and prepi, we must conclude that they express matching modalities".

Turning now to the combination of tha with the PNP, it is agreed that these constructions convey the future interpretation yet as Giannakidou (2012) suggests, they are not devoid of the epistemic reading especially when a time adverbial is not present. To further illustrate this point the following example is given:

(23) Context: It's late, the weather is bad, and we know Ariadne is travelling. You worry, and I want to reassure you and say:

Min anisixis. $\quad$ i Ariadne tha ftasi (epistemic)

Not worry IMPER, 2SIN. the Ariadne will arrive PNP, 3SIN

'Don't worry. Ariadne will arrive.'

In such contexts, both interlocutors are not particularly interested in the time of the event (temporal reading), instead they are interested in the degree of certainty of the occurrence of the event (modal reading). Giannakidou (2012) names interpretations related to examples such as (23) epistemic future since on the one hand there is a clear forward shifting of the event, but on the other there is also an epistemic reading.

The absence of future-time reference is also possible in generic, atemporal sentences such as the one already discussed in (17), quoted below as (24):

(24) Kathe proi tha sikothi, tha pji to kafedaki tu, tha djavasi tin efimerida tu ke kata tis 8.30 tha figi gia to grafio tu

'Every morning he will get up, drink his coffee, read his newspaper and at approximately 8.30 he will leave for the office.'

Here again there is no time adverbial in the utterance. It is therefore argued that in tha with PNP combinations the presence of time adverbials determines in a great extent whether the epistemic reading will surface or not.

The claim that tha is not a future tense marker but that it is a modality operator with present perspective is thoroughly discussed in a study focusing on the dependency of the PNP form. Giannakidou (2009) observes that 'non-past' forms in Modern Greek are not equivalent to a present. More specifically, the INP is not a present tense but it is "used for habitual and generic statements, as well as to denote progressive and ongoing events" (Giannakidou 2009: 1896). Now, in cases where the imperfective is used for the progressive, it denotes the function PROG. By contrast, when used generically, the imperfective contributes GEN. The output is an interval during which generic quantification takes place (Giannakidou 2009). It is therefore assumed that the INP does not make reference to a specific time.

The PNP cannot function as a present tense either. It is suggested (Giannakidou $2009,2012)$ that the dependent nature of the PNP is attributed to its inability to make reference to the utterance time. As it is proposed, the PNP contains a time interval $(t, \infty)$ whose left boundary $t$ is a non-deictic variable. Following this, non-past in Modern 
Greek should have the following semantic representation introduced in Abusch (2004) ${ }^{4}$ (Giannakidou 2009: 1899):

$$
\text { (25) }[\text { non-past }]=\lambda \mathrm{P} \lambda \mathrm{t} \mathrm{P}((t, \infty))
$$

In Abusch's (2004) analysis since $t$ is a non-deictic variable, it must be bound by $n$ (PRES, utterance time) in order to be licensed. In a real present tense this variable receives its $n$ 'now' value (referring to the utterance time) from a PRES feature. Nevertheless, "the Greek non-past contains no higher temporal information, that is, no PRES and it will thus require some other element to supply n" (Giannakidou 2009: 1899). As a result, the PNP is treated as a temporal polarity item which will need a particular licensing context in order to receive the missing $n$ or PRES feature and therefore, to acquire a time value

In the case of the INP, which conveys either a generic or a progressive interpretation, it is the time adverbials that provide the relevant time interval which replaces $(t, \infty)$. By way of illustration consider the example (in Giannakidou 2009):

(26) O Jianis grafi sixna

'John writes often.'

OFTEN $t[t \in \mathrm{C} \wedge t \subseteq i$ : write $(\mathrm{j}, t) \wedge i=(t, \infty)]$

As Giannakidou (2009: 1900) suggests, "[i]n this sense, the problematic interval $(t, \infty)$ is replaced by the generic interval $i \ldots$ and the result is a statement with no direct reference to the utterance time". In the same fashion, adverbials or temporal expressions like tora (Eng. now) or olo to proi (Eng. all morning) provide a time interval which binds the variable $t$ giving thus the progressive readings. (27):

The explanation described above does not yet hold for the PNP. Consider example

(27) *O Jianis $\gamma$ rapsi PNP sixna / tora / olo to proi

'John writes often / now / all morning.'

The addition of adverbials or temporal expressions does not improve the illicit PNP. Therefore, the need for $n$ to be introduced still remains. Giannakidou $(2009,2012)$ suggests that the PNP receives $n$ from particles such as tha. This motivates the introduction of a Now-TP into the syntactic structure with tha being its head (Now-T). This syntactic structure is illustrated in the following example:

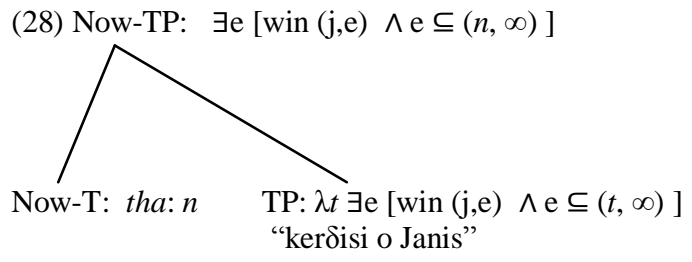

\footnotetext{
${ }^{4}$ According to Abusch (2004: 39), "in the substitution operator, $t$ is a bound variable that corresponds to the tense argument of will. For a top-level occurrence of will, the effect is to substitute $(n, \infty)$ for $n . "$
} 
It is thus suggested that the particle tha semantically functions as the present tense ${ }^{5}$ which is missing from the PNP verb form - and at the same time provides a satisfying explanation for the dependency of the PNP to particles such as tha.

Eventually, concerning the future-time interpretation of tha constructions Giannakidou (2012) and Giannakidou \& Mari (2012) argue that it crucially depends on the time adverbials as well as the $(t, \infty)$ interval which is available in the non-past forms. More accurately, it is put forward the presence of an adverb "provides direct evidence about a time, and this time serves to constrain the temporal space for the location of the eventuality denoted by the VP" (Giannakidou \& Mari 2012: 267). Therefore, there is a domain restriction which generates the future reading giving thus the force of a prediction. By contrast, when there is no adverb we can have either an epistemic present or an epistemic future interpretation. In the first case, "the time of the evaluation of the VP coincides with $t_{u}$ (utterance time). On the epistemic future reading, the time of the evaluation of the VP is forward shifted [...] possibly because of the non-past which makes available the interval $(t, \infty)$ anyway" (Giannakidou \& Mari 2012: 268).

To sum up, it is agreed that tha is not a pure future tense marker. In contrast to Tsangalidis (1999), who suggests that tha does not qualify as a modal either, but that it is an autonomous entity (a future-gram), Giannakidou (2012) and Giannakidou \& Mari (2012, 2013 and 2014) argue that tha is an epistemic modal operator which is temporally anchored at the utterance time. Moreover, evidence appears to play an important role in the final interpretation of tha sentences according to the analyses presented. Evidence, either concerning the temporality of the event (in the form of an adverb of time) or the eventuality itself, is what narrows down the temporal domain and triggers future readings.

\section{Futurity communicated: Towards a pragmatic analysis}

In the accounts presented here the future readings of tha sentences arise as a result of their semantic meaning along with the interaction of the immediate linguistic context (adverbs of time, etc.).

Nevertheless, a closer look at the data shows that the presence of a tha construction is neither a necessary, nor a sufficient condition for future-time reference ${ }^{6}$. This can be interpreted in two ways; on the one hand, as has already been shown, tha constructions can convey purely epistemic readings, for instance, when tha is combined with the INP as in (29) or the PP.
(29) i Ariadni tha kimate
tora
The Ariadne will sleep INP, 3sin now
'Ariadne must be sleeping now.'

What is more, even tha with PNP, which is considered the typical 'future' construction, does not convey a temporal (future) interpretation in generic contexts.

\footnotetext{
${ }^{5}$ Apart from tha, the so-called future particle, the semantic function of the present tense is also given by the subjunctive $n a$, the optative $a$ s and conditional an (Giannakidou 2009).

${ }^{6}$ Comrie (1985) argues the same for the use of the auxiliary will in English.
} 
(30) Kathe fora pu tha vreksi PNP o dromos plimirizi Every time that will rain the street floods 'Every time that rains the street floods.'

On the other hand, future-time reference can also be communicated by other means without the use of the tha constructions. Consider the case where the INP verb form (traditionally referred to as present tense) is used to refer to a future event:

(31) To treno anachori stis 10

"The train departs at 10."

In addition, $n a$ constructions, which typically express subjunctive mood, also usually convey reference to the future.

(32) i Eleni etimazetai na SUBJ pai sto Londino 'Eleni prepares for going to London.'

It becomes evident then that future-time reference is not marked by a particular form. It is not part of the coded linguistic content. On the contrary, as I will propose here, it follows as a conversationally communicated interpretation based on the semantic information of what is coded.

More precisely, I agree that tha always contributes an epistemic modal semantic base (in the spirit of Giannakidou (2012) and Giannakidou \& Mari (2012)) and I shall argue that: a) the non-past, non-present (i.e. future-time) reading of tha with INP arises as a temporal domain restriction due to the presence of direct evidence (such as time adverbials, $1^{\text {st }} / 2^{\text {nd }}$ person), and b) the non-past, non-present reading of tha with PNP, arises as a default, i.e. pragmatically enriched and a more informative reading of the modal semantic base, and that it is not influenced by the presence of a time adverbial. A way forward is to suggest that future-time reference in Modern Greek arises as a kind of presumptive meaning ${ }^{7}$ related to the I-principle as developed and discussed in Levinson (2000).

\subsection{The neo-Gricean I-implicature}

In a reductionist variant of the original Gricean theorizing (Grice 1975, 1989), Levinson (1987, 1991, 1995, 2000) proposes three basic heuristics or principles which license default interpretations. These are the I-principle ('say as little as necessary'), the Qprinciple ('do not say less than you know') and the M-principle ('Do not use a prolix, obscure or marked expression without reason'). Here, I will focus on the I-principle which is originally defined as follows:

The I-Principle (Levinson 2000: 114-115)

Speaker's Maxim: The Maxim of Minimization.

\footnotetext{
${ }^{7}$ The idea that tenses generate implicatures and therefore there is a need for a pragmatic account is not a novel one, cf. Comrie (1985).
} 
'Say as little as necessary', i.e. produce the minimal linguistic information sufficient to achieve your communicational ends (bearing the Q-principle in mind).

Recipient's corollary: The enrichment rule.

Amplify the informational content of the speaker's utterance, by finding the most specific interpretation, up to what you judge to be the speaker's m-intended point. Specifically:

(a) Assume that stereotypical relations obtain between referents or events, unless (i) this is inconsistent with what is taken for granted; (ii) the speaker has broken the Maxim of Minimization by choosing a prolix expression.

(b) Assume the existence of actuality of what a sentence is 'about' if that is consistent with what is taken for granted.

(c) Avoid interpretations that multiply entities referred to (assume referential parsimony).

(d) Assume the existence or actuality of what the sentence is about if that is consistent with what is taken for granted.

The central idea behind the I-principle is that the use of a semantically general expression I-implicates a semantically specific interpretation. More accurately, the implicature engendered by the I-principle is one that accords best with the most stereotypical and explanatory expectation given our knowledge about the world. The Iprinciple covers a variety of inferences such as inference to the stereotype (34) and conjunction buttressing (35) among others (cf Levinson 2000: 117 for more examples).

(34) Paul was waiting for the nurse to give him his medicine

+> Paul was waiting for the female nurse to give him his medicine

(35) Paul pressed the button and the lights turned on

$+>$ Paul pressed the button and then the lights turned on

$+>$ Paul pressed the button and therefore the lights turned on

In (34) an I-implicature is triggered by the stereotypically held expectation that a nurse is most of the times a female nurse, while in (35), the use of 'and' can implicate temporal sequence or causal connectedness.

Despite the great variation among I-inferences, they share certain common properties $^{8}$. As mentioned above, I-inferences are inferences to more specific interpretations. Moreover, they are positive in nature. As Levisnon (2000: 119) notes, "the extension of what is implicated is a proper subset of the extension of what is said, the extension being restricted positively". In addition, I-inferences do not refer to something that could have been said but was not said as it is the case with the other neoGricean implicatures which are based on scales. The default readings given by the Iprinciple are inferences from structure and meaning to further presumptive meanings. As Levinson (2000: 22) notes, they are "based not on direct computations about speakerintention, but rather on general expectations about how language is normally used".

\footnotetext{
${ }^{8}$ I-inferences also exhibit the typical properties of all non-monotonic inferences, namely, defeasibility, non-detachability, calculability, conventionality and reinforcability.
} 


\section{A neo-Gricean account of future-time reference in Modern Greek}

Based on the discussion so far, I would like to propose a partial neo-Gricean pragmatics apparatus for the interpretation of future-time reference in Modern Greek, which is spelled out in (36) below:

(36)

A neo-Gricean pragmatic apparatus for the interpretation of future-time reference in Modern Greek.

(a) particle tha contributes an epistemic modal semantic base (in the sense of Giannakidou 2012 and Giannakidou \& Mari 2012).

(b) Interpretation principle

i. The combination of tha with the INP, and in the absence of any particular context, will express an epistemic modal interpretation referring to the utterance time, unless there is direct evidence available (time adverbials, $1^{\text {st }} / 2^{\text {nd }}$ person, physical evidence). In this case, the non-past modal base is temporally restricted to non-past, non-present contributing thus an epistemic future reading.

ii. The combination of tha with the PNP will I-implicate a more specific future interpretation.

Armed with this apparatus, let me now return to the original question addressed at the beginning of the paper, a question of how hearers induce future readings of tha constructions despite the fact the latter do not have unambiguous future-time reference as part of their semantic, coded, meaning. Let me start from the combinations of tha with the INP. Considering the following example:

(37) i Eleni tha kimate jafto mi tin paris tilefono the Eleni will sleep INP so not her call 'Helen will be sleeping, so don't call her.'

In the absence of any specific context, (37) will receive a preferred epistemic present interpretation. Thus the hearer confronted with such an utterance makes an inference about the state of affairs at the utterance time. The epistemic modal reading follows from the proposed evidential nature of tha at the semantic level of interpretation (see Giannakidou 2009, Giannakidou \& Mari 2012). More accurately, the speaker based on indirect evidence assumes that Helen will be sleeping at the utterance time (for instance the speaker may be aware of Helen's habits, plans, etc.).

Consider now the case in which Helen is present when the speaker utters (37). In this case, the epistemic present reading is not possible since the speaker has direct evidence (based on physical contact) that Helen is not sleeping. As already noted, physical evidence is in fact strong direct evidence possessed by the speaker and thus, the non-past modal base will be temporally restricted (in the spirit of Giannakidou 2012) to non-past, non-present. The epistemic reading remains, but it refers to the future.

Equally, the epistemic present reading is blocked when there is a time adverbial, as in (38) or the subject is in the first or second person, as in (39). 
(38) i Eleni tha kimate avrio the Eleni will sleep INP tomorrow.

'Helen will be sleeping tomorrow.'

(39) Epidi tha taksidevo den borume na vrethoume.

Because will travel INP, $1^{\mathrm{ST}}$ not can to meet

'Because I will be travelling, we can't meet.'

In (38), the speaker by using the time adverb avrio (Eng. tomorrow) indicates that he is in possession of some direct evidence about the time of the event. This evidence will serve as a domain restrictor for tha shifting its eventuality towards the future (Giannakidou 2009, Giannakidou \& Mari 2012). What is more, in example (39), it is obvious that the speaker definitely has direct evidence about himself at any given time. Thus, the speaker cannot make inferences about himself or even about the hearer at the utterance time. As already noted, the fact that the first and the second person are more likely to express futurity than the third person is also observed in Tsangalidis (1999 following Heine 1995). In particular, Heine (1995: 25) notes that "epistemic (present) modality correlates most strongly with third-person and least strongly with first-person." This tendency is compatible with the evidential nature of tha constructions.

Epistemic present interpretations do not normally go through in the $1^{\text {st }}$ and the $2^{\text {nd }}$ person contexts. Yet, there are cases in which future-time reference is possible (see Tsangalidis 1999: 212).

(40) tha kimame- INP, $1^{\mathrm{ST}}$ akoma jafto den katalaveno ti mu les.

'I will still be asleep and that is why I can't understand what you are talking about.'

As Tsangalidis (1999) notes, the epistemic present reading of the $1^{\text {st }}$ and the $2^{\text {nd }}$ person in examples such as (40), although possible, is not the default one, but it always needs a particular context to arise.

Let us now focus on the combination of tha with the PNP which is the 'pure' future tense in Modern Greek. At the risk of redundancy, it is important to recall that in terms of temporality tha with PNP sentences are used in the majority of cases (apart from the timeless or atemporal constructions examined earlier in the discussion) to denote that the time of the event follows the time of the utterance (futurity) whereas in certain restricted contexts they can also receive a timeless or atemporal interpretation. Nevertheless, tha with PNP sentences can never indicate an event overlapping with the time of the utterance despite containing a $[- \text { past }]^{9}$ verb form. Following our apparatus, the default future interpretation of tha with PNP constructions is an I-inference. Consequently, sentence (41) will I-implicate (42), (+> stands for 'implicates'):

\section{(41) i Eleni tha fiji}

The Eleni will leave PNP

'Helen will leave.'

\footnotetext{
${ }^{9}$ This also shows that in Modern Greek the category [-past], which does not produce reference to the utterance time is distinct from the category [+present], which does.
} 
(42) $+>$ i Eleni den ehi fiji akoma

'Helen hasn't left yet.'

The coded content of (41) can be spelled out as follows: The particle tha is a modal operator and semantically contributes $n$ (i.e. the utterance time) hence it has a present perspective. The PNP, after receiving $n$ from the particle tha, denotes an open forward looking interval, namely, $(n, \infty)$. Hence, the coded content of tha with the PNP is nonpast, including thus the utterance time (present) and also giving the possibility of a future reading. Nevertheless, what is actually communicated is the future reading. In other words, at the level of interpretation tha with the PNP conveys the non-past, non-present reading 'Helen hasn't left yet', which is a narrowing down of what is said. This interpretation arises as an I-enriched, more specific, temporal interpretation. The interpretation in (42) is more specific and more informative in the sense that from the non-past the speaker will I-implicate a non-past, non-present (i.e. future) reading.

Turning now to the role of adverbs, as we have seen in tha with INP constructions, the presence of an adverb of time which encodes future time forward shifts the eventuality. Nevertheless, this is not the case with tha with PNP sentences. The interpretation associated with the use of tha with PNP appears to be strong and generalised in the sense that it does not depend on any kind of context (such as time adverbs, etc.). In other words, it is not a one off interpretation based on a particular situation.

(43) i Eleni tha fiji avrio

The Eleni will leave PNP tomorrow

'Helen will leave tomorrow.'

+> i Eleni den ehi fiji akoma

'Helen hasn't left yet.'

I would agree therefore with Jaszczolt (2006) that a sentence such as (41) evokes the same sense of futurity with (43), and I would also suggest that they give rise to the same I-implicated future interpretation.

It can be argued that here the role of time adverbs is not to convey future-time reference, but to indicate that the speaker has more evidence about the state of affairs described by the verb. By presenting more evidence about the time the speaker actually minimises the possibility of proposition $p$ being a non-possible world. Thus, the evidence provided by the adverb of time weakens the potential epistemic interpretation which is always possible given the modal semantic base of the construction. In this sense, the speaker appears more committed to the truth of the proposition expressed and he intends reference to the future time in the real world without reference to possible worlds (epistemic modal reading).

\subsection{Arguments for an I-inference}

The future interpretation of tha with the PNP, as seen so far, has the hallmarks of an Iinference. Let us recall here a typical case of an I-inference, namely, conjunction buttressing. 
(44) Paul pressed the button and the lights turned on

$+>$ Paul pressed the button and then the lights turned on

$+>$ Paul pressed the button and therefore the lights turned on

In (44) the I-principle allows us to enrich the interpretation of a conjunction to a more informative temporal sequential, or causal, relation. In the same sense, in the case of future-time reference, from the non-past modal semantic base the speaker infers a nonpast, non-present (i.e. future) temporal reading. Thus, future readings in Modern Greek are parasitic on and additional to semantic information and they exhibit a typical property of I-inferences in that, as Levinson put it (2000: 116), "they do not just entail what is said but they introduce semantic relations absent from what is said, and in that sense can be said to reshape the proposition expressed."

Moreover, the future reading of tha with the PNP is stereotypical. In essence, there is a strong presumption that tha with PNP is understood as clearly future oriented and therefore, if the speaker had intended another interpretation but the future one, the speaker should have used a different way of saying it. In other words, it would be redundant to spell out more explicitly the future reading of examples like (41) and this is a typical property of I-inferences (Levinson 2000). Finally, the future interpretation has a positive nature in the sense that "the extension of what is implicated is a proper subset of the extension of what is said" (Levinson 2000: 119).

The future-time I-implicature, being a non-monotonic inference, is also expected to exhibit the key properties of conversational implicatures. At first, the future interpretation of tha with PNP is defeasible in certain contexts. By way of illustration, consider (45) and (46).

(45) $\mathrm{i}$ Eleni tha fiji avrio

The Eleni will leave PNP tomorrow

'Helen will leave tomorrow.'

+> i Eleni den ehi fiji akoma

'Helen hasn't left yet.'

(46) i Eleni tha fiji avrio an den ehi fiji idi

The Eleni will leave PNP tomorrow if not has left already

'Helen will leave tomorrow if she isn't already gone.'

(implicature 'Helen hasn't left yet.' is cancelled by the additional premises)

Here, the future I-implicature in (45) is cancelled in (46) since it is overtly denied without any obvious contradiction.

However, it has to be noted here that cancellation is not possible in contexts where there is direct physical evidence. For example, if (45) is uttered while Helen is present in the discussion, the speaker cannot overtly cancel the implicated content by adding 'if she isn't already gone' since the speaker can see that Helen is still there with him. This phenomenon is also observed in other implicature types such as the Quantity implicatures.

(47) a) Some of the cars are red

b) $+>$ not all of the cars are red 
The utterance in (47a) will normally convey the assumption in (47b). This happens because the use of some (which is semantically weak) instead of its contrastive semantic alternate, namely, all (which is semantically stronger) will implicate the negation of the interpretation associated with the use of the stronger expression, i.e. not all. Hence, in a rational and co-operative exchange, if the speaker knew that all of the cars were red, the speaker should have said so. The reading in (47b) being conversationally implicated can be explicitly cancelled without contradiction.

(48) a) Some of the cars are red, in fact all of them are ('not all of the cars are red' is cancelled)

Now, imagine that the speaker is looking at ten cars only four of which are red. In this case, direct evidence would block the cancelation context since indeed only some of the cars are red and therefore the speaker could not go on to suggest that in fact all of them are red since this would not be consistent with evidence in the real world.

Moreover, as noted above, the future-time interpretation is not attached to the form of tha constructions. In other words, a future-time reading can be successfully conveyed without the use of a tha construction.

(49) i Eleni etimazetai na SUBJ pai sto Londino

'Helen prepares for going to London.'

+> i Eleni den ehi pai sto Londino akoma

'Helen hasn't gone to London yet.'

(50) As fiji i Eleni de me niazi

'Let Helen leave, I don't mind.'

+> i Eleni den ehi fiji akoma

'Helen hasn't left yet.'

The primary reading of (49) and (50) is subjunctive and optative respectively, yet they both have a secondary future interpretation which is parasitic on the semantic information involved. This future reading is also defeasible as it happens in tha with PNP combinations. Future-time reference is also possible with the present tense verb form ${ }^{10}$.

(51) i Eleni fevji avrio

The Eleni leaves tomorrow

'Helen will leave tomorrow.'

\footnotetext{
${ }^{10}$ Jaszczolt (2011: 4) notes that "the present is used to convey a pragmatic overlay pertaining to the degree of commitment to the truth of the ensuing event or the degree of planning; the overall message reads to the effect that, other things being equal, this is what has been planned for tomorrow, or this is what is intended for tomorrow. In short, although the present verb form is not the default way of referring to the future in either of the languages under discussion, it can be applied for this task for the purpose of increasing the degree of commitment on the part of the speaker".
} 
In such cases, however, the future reading seems to be conditioned by the presence of the adverb of time since in the absence of an adverb, the time of reference is the utterance time.

Finally, the future-time reading can also be reinforced with no sense of redundancy. Consider the example.

(52) i Eleni tha fiji avrio, den exi fiji akoma

The Eleni will leave PNP tomorrow not has left yet

'Helen will leave tomorrow, she hasn't left yet.'

It is shown then that the future-time interpretation of tha with PNP constructions is pragmatically induced and it is not part of what is coded. In particular, the future reading arises as a default I-implicature which expresses a more informative reading of the modal semantic base.

\section{Conclusion and further implications}

In this paper, I have considered a pragmatic analysis of future-time reference in Modern Greek. I mainly examined the distributional basic facts of tha with PNP and tha with INP sentences and I presented the current accounts in the literature. Based mainly on the analysis proposed by (Giannakidou 2009, 2012 and Giannakidou \& Mari 2012), I argued for a generalized pragmatic account for future-time reference in Modern Greek in terms of the neo-Gricean pragmatic theoretical framework in the spirit of Levinson (2000). More precisely, assuming that tha constructions contribute an epistemic modal semantic base (Giannakidou 2009, 2012 and Giannakidou \& Mari 2012), I claimed that future interpretations of tha with PNP combinations arise as I-implicatures. In essence, it was proposed that given the semantic base, future-time reference arises as a default implicature from the lack of further specification to the lack of need for it.

Finally, this paper has two major implications for current thinking on future-time reference. In the first place, what is actually proposed is that future-time reference is a special case of modality and that the future reading arises when it is more informative than the epistemic modal one. The idea that future time reference can be modal is not novel. More precisely, Giannakidou $(2009,2012)$ and Giannakidou \& Mari (2012) also argue that future is a kind of epistemic modality and more specifically that it is related to evidentiality. What is more, Jaszczolt (2006), in an analysis of the English will within the Default Semantics framework, suggests that the different readings of will can be better explained by a scale of epistemic modality ${ }^{11}$ showing thus that future-time reference can be modal.

Secondly, it appears that future-time reference is a product of the division of labour between semantics and pragmatics. The coded content of the traditionally called 'future tense' is non-past, epistemic and it makes reference to possible worlds, leaving also open the possibility of a future reading. Nevertheless, what is actually communicated is a default non-past, non-present meaning, which is a subset of the meaning of the semantic base. The future interpretation arises then as an I-enriched more specific, temporal

\footnotetext{
${ }^{11}$ For more arguments for temporality as epistemic modality see also Jaszczolt $(2009,2013)$.
} 
interpretation based on the semantic content of what is said and it is consistent with what the speaker intends to communicate.

\section{References}

Abusch, Dorit. (2004). "On the temporal composition of infinitives". In J. Guéron, \& J. Lecarme (Eds.), The Syntax of Time (1-34). Cambridge, Mass, The MIT Press.

Bybee, Joan L. \& Östen Dahl (1989). "The creation of tense and aspect systems in the languages of the world". Studies in Language, 13.1, 51-103.

Bybee, Joan L., Revere D. Perkins \& William Pagliuca (1994). The evolution of grammar: Tense, aspect and modality in the languages of the world. Chicago \& London: The University of Chicago Press.

Comrie, Bernard (1976). Aspect. Cambridge Textbooks in Linguistics. Cambridge: Cambridge University Press.

Comrie, Bernard (1985). Tense. Cambridge Textbooks in Linguistics. Cambridge: Cambridge University Press.

Condoravdi, Clio. (2002). Temporal interpretation for modals. Modals for the present and modals for the past. In D. Beaver al. (eds.), Stanford Papers on Semantics. Stanford: CSLI, 59-87.

Copley, Bridget (2009). The Semantics of the Future. Outstanding Dissertations in Linguistics. New York: Routledge.

Dahl, Östen (1985). Tense and Aspect Systems. Oxford: Blackwell.

Enç, M. (1996). Tense and Modality. In S. Lappin (ed.), Handbook of Contemporary Semantic Theory. Oxford : Blackwell.

Giannakidou, Anastasia (2009). "The dependency of the subjunctive revisited: temporal semantics and polarity". Lingua, 120, 1883-1908. DOI: 10.1016/j.lingua.2008.11.007

Giannakidou, Anastasia (2012). "The Greek future particle as an epistemic modal". In Z. Gavriilidou, A. Efthimiou, E. Thomadaki and P. Kambakis-Vougiouklis (Eds.), Proceedings of $10^{\text {th }}$ ICGL (48-61) Democritus University of Thrace.

Giannakidou, Anastasia \& Alda Mari (2012). "A modal analysis of Greek and Italian future morphemes". Proceedings of Sinn und Bedeutung 17: 255-270.

Giannakidou, Anastasia \& Alda Mari (2013). "A two dimensional analysis of the future: modal adverbs and speaker's bias". Proceedings of the Amsterdam Colloquium 2013: 115-122.

Giannakidou, Anastasia \& Alda Mari (2014). The future in Greek and Italian: truth conditional and evaluative dimensions. Ms.

Grice, Paul (1975). "Logic and Conversation". In P. Cole \& J. Morgan (Eds.), Syntax and Semantics 3: Speech Acts (41-58). New York: Academic Press.

Grice, Paul (1989). Studies in the Way of Words. Cambridge, Mass: Harvard University Press.

Heine, Bernd (1995). Agent-oriented vs. epistemic modality: some observations on English modals. In J. Bybee \& S. Fleischman (Eds.), Modality in grammar in discourse: Typological Studies in Language 32 (17-53) Amsterdam: John Benjamins.

Holton, David, Mackridge, Peter \& Philippaki-Warburton, Irene (1997). Greek: A Comprehensive Grammar of the Modern Language. London, Routledge. 
Jaszczolt, M. Kasia (2006). Futurity in Default Semantics. In: K. von Heusinger and K. Turner (Eds.), Where Semantics Meets Pragmatics. (471-492) Oxford: Elsevier.

Jaszczolt, M. Kasia (2009). Representing Time: An Essay on Temporality as Modality. Oxford: Oxford University Press.

Jaszczolt, M. Kasia (2011). Time as degrees of epistemic commitment. In: P. Stalmaszczyk (Ed.), Turning Points in the Philosophy of Language and Linguistics. (19-34) Frankfurt: Peter Lang.

Jaszczolt, M. Kasia (2013). Temporality and epistemic commitment: An unresolved question. In: K. Jaszczolt and L. de Saussure (Eds.), Time: Language, Cognition, and Reality. (193-209) Oxford: Oxford University Press.

Joseph D. Brian (1983). The synchrony and diachrony of the Balkan infinitive. A study in aerial, general and historical linguistics. Cambridge Studies in Linguistics Supplementary Volume. Cambridge University Press.

Kissine, M. (2008). Why will is not a modal. Natural Language Semantics, 16 (2): 129-55. DOI: $10.1007 / \mathrm{s} 11050-008-9028-0$

Levinson C. Stephen (1987). " Pragmatics and the grammar of Anaphora: A partial pragmatic reduction of binding and control phenomena". Journal of Linguistics, 23, 379-434. DOI: http://dx.doi.org/10.1017/S0022226700011324

Levinson C. Stephen (1991). "Pragmatic Reduction of Pragmatic Conditions Revisited". Journal of Linguistics, 27, 107-161.

DOI: http://dx.doi.org/10.1017/S0022226700012433

Levinson, S.C. (1995) 'Three levels of meaning', in F.R. Palmer (ed.) Grammar and Meaning. Essays in Honour of Sir John Lyons, Cambridge: Cambridge University Press.

Levinson C. Stephen (2000). Presumptive Meanings: The Theory of Generalized Conversational Implicature. Cambridge: The MIT Press.

Ludlow, Peter (1999). Semantics, Tense and Time: An Essay in the Metaphysics of Natural Language. Cambridge: The MIT Press.

Mackridge, Peter (1985). The Modern Greek Language: A Descriptive Analysis of Standard Modern Greek. Oxford: Oxford University Press.

Mari, Alda. (2009). The future : how to derive the temporal interpretation. JSM 2009, Paris VII.

Mari, Alda. (2010). Temporal reasoning and modality. Invited talk Temptypac Workshop, Paris VIII.

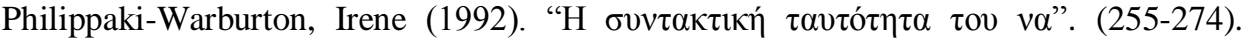
Studies in Greek Linguistics.

Philippaki-Warburton, Irene (1994). Verb movement and clitics in Modern Greek. In Philippaki-Warburton I., Nicolaidis, K. \& Sifianou, M. (eds.), Themes in Greek CLITICS AND DOUBLING (53-60), Current issues in linguistic theory 117. Amsterdam: John Benjamins.

Rivero, Maria-Luisa (1994). Clause structure and v-movementin the languagesof the balkans. Natural Language and Linguistic Theory, 12: 63-120. DOI: 10.1007/BF00992746

Sarkar, Anoop (1998) "The Conflict Between Future Tense and Modality: The Case of Will in English," University of Pennsylvania Working Papers in Linguistics: Vol. 5: Iss. 2, Article 6. 
Smith, Carlota (1991). The parameter of aspect. Studies on Linguistics and Philosophy 43. Dordrecht, Boston, London: Kluwer Academic Publishers.

Squartini, Mario (2004). "Disentangling evidentiality and epistemic modality in Romance”. Lingua, 114: 873-895. DOI: 10.1016/S0024-3841(03)00064-0

Tsangalidis, Anastasios (1999). Will and Tha: a comparative study of the category of the future. Thessaloniki: University Studio Press.

Veloudis, Jiannis \& Philippaki-Warburton, Irene, 1983. The subjunctive in Modern Greek. In Studies in Greek Linguistics. Proceedings of the $4^{\text {th }}$ annual meeting of the Department of Linguistics (151-168). University of Thessaloniki.

Xidopoulos, Georgios (1996). Tense, aspect and adverbials in Modern Greek. Unpublished Ph.D. Thesis. University College London.

\begin{abstract}
About the author
Michael Chiou (BA, MA, PhD in Linguistics). My main research interests are in pragmatics and especially the pragmatics-syntax and pragmatics-semantics interfaces. Current research involves anaphora in Modern Greek and the interpretation of time in language. I have taught and supervised for pragmatics, semantics and syntax at the University of Hertfordshire and the University of Cambridge.
\end{abstract}

